\title{
Wind capacity factor calculator
}

\section{H. Kekana ${ }^{1^{*}}$, G. Landwehr ${ }^{2}$}

1. South African Wind Energy Association, RE Hub 53 Dudley Road Corner Bolton Avenue, Parkwood 2193, Gauteng South Africa. https://orcid.org/0000-0001-9799-394

2. Council for Scientific and Industrial Research, Energy Centre, Meiring Naudé Road, Brummeria, Pretoria, 0001, South Africa. https://orcid.org/0000-0001-6979-6578

\begin{abstract}
The wind capacity factor calculator is developed to perform two main tasks: to estimate the annual energy production from the wind resource at any location in South Africa, and to compare the two datasets used in its operation with standard error analysis to determine whether both datasets are suitable for use. This paper focuses on how the software was developed and on error analysis between the CSIR PV/ wind aggregation study data and the latest Wind Atlas for South Africa data. The results will indicate the way forward after determining whether the error found between the two datasets is significant enough to replace the former with latter, going forward.
\end{abstract}

Keywords: wind energy, efficiency, capacity factor, Pearson Correlation Coefficient, mean absolute error, Wind Atlas for South Africa

Journal of Energy in Southern Africa 30(2): 118-125

DOI: https://dx.doi.org/10.17159/2413-3051/2019/v30i2a6451

Published by the Energy Research Centre, University of Cape Town ISSN: 2413-3051

This work is licensed under a Creative Commons Attribution-ShareAlike 4.0 International Licence https://journals.assaf.org.za/jesa

Sponsored by the Department of Science and Technology

Corresponding author: Tel: +27 670690702; email:

hlologelom9k@gmail.com 


\section{Introduction}

South Africa is endowed with both a profitable wind resource in the southernmost parts of the country and solar resources in the north-western parts. The wind resource is most prolific in the Eastern and Western Cape provinces, which include a large portion of the $2800 \mathrm{~km}$ long South African coastline [1]. Figure 1 illustrates the wind resource found in South Africa and the areas where it is most prominent, as per the latest Wind Atlas of South Africa (WASA) high resolution wind resource results.

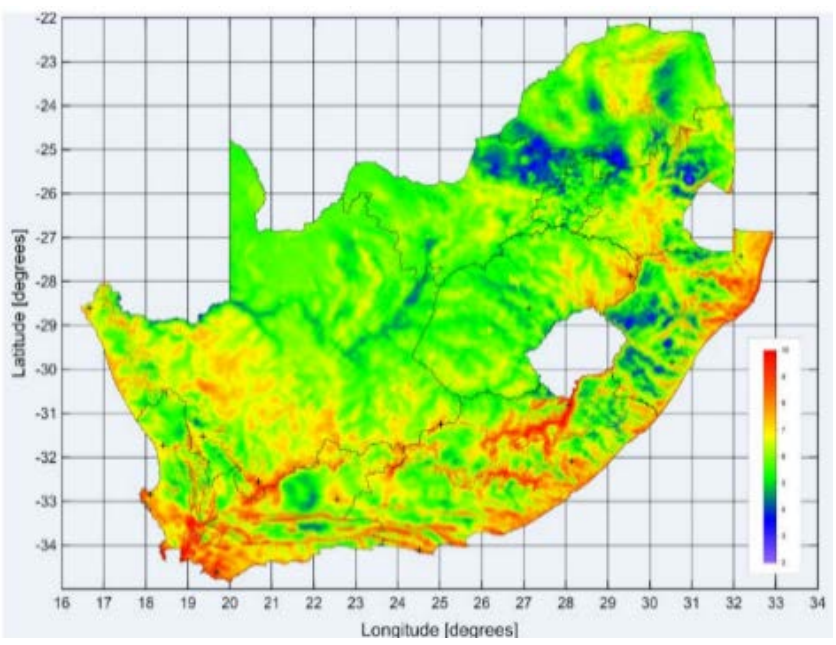

Figure 1: High resolution wind resource map of the Wind Atlas of South Africa domain [2].

The Danish Technical University developed data for this wind resource, collected over a five-year period at 15-minute intervals. A further dataset optimised for photovoltaic (PV) and wind resources was developed by Fraunhofer for the Council for Scientific and Industrial Research (CSIR) in 2016 to indicate an optimised energy mix per $5 \times 5 \mathrm{~km}$ pixel across South Africa. It is through the studies raw wind resource data that the wind capacity factor calculator has been developed, using Python as the chosen programming language. The five-year timeseries data was averaged and then converted into a probability density function, which predictably resulted in a Weibull distribution. This data for four heights $(50,80,100,150 \mathrm{~m})$ above ground level could then be used in conjunction with existing power curves for various wind turbines to calculate the annual energy production (AEP) for a particular location in South Africa.

The intention of the project is ultimately to build a tool which serves the wind industry by providing reliable information which can then be used to help determine whether to proceed with a pre-feasibility study for a wind-farm power plant according to a location's wind properties. By simply inputting the location's coordinates and turbine type, the user should be able to obtain a short report on the wind energy potential properties of the location. The wind capacity factor calculator (WCFC) is developed to perform two main tasks: determine the wind power output at any location in South Africa, and compare two datasets used in its operation to provide a metric for data reliability.

\section{Background}

The significance of being able to determine at a high level a site's AEP from the wind resource can vastly affect the choice to pursue further feasibility studies or not. As a next step, wind prospectors can then use the measure, correlate and predict (MCP) method to simulate and determine more accurate results [3].

\subsection{Power curves and AEP}

Figure 3 demonstrates a standard power curve, showing the wind turbine power generated relative to the wind speed. This is used with the wind speed values to output the AEP of a particular position.

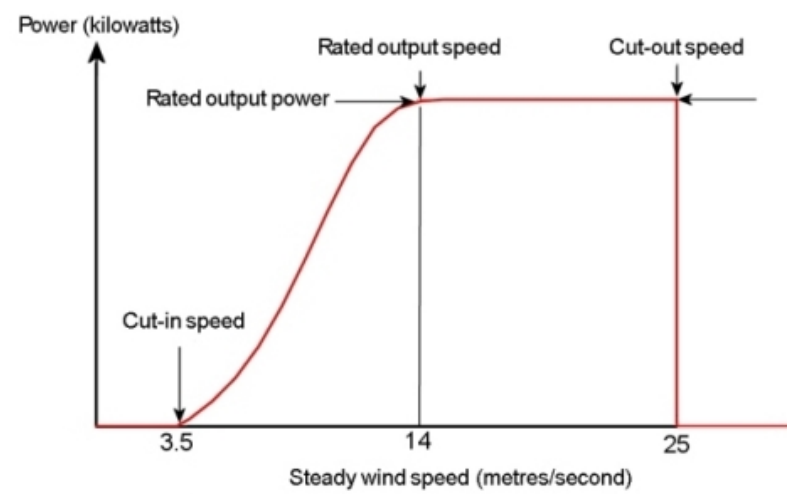

Typical wind turbine power output with steady wind speed.

Figure 2: Power output from wind turbine over varying wind speeds [4].

\subsection{Capacity factor}

The capacity factor is an indicator of how well a particular wind turbine or wind farm can utilise the available wind resource. The capacity factor is calculated as a percentage by taking the ratio of the AEP to the theoretical maximum output [5].

\section{Data and methods}

\subsection{Data description}

The data used for the analysis comes from the CSIR $\mathrm{PV} /$ wind aggregation study's raw wind resource data (dataset 1) and the latest WASA reduced data (dataset 2). There are four main methods to estimate the AEP:

- PDF (probability density function);

- $\mathrm{CDF}$ (cumulative distribution function);

- survival function/reliability function; and

- hazard function

Figure 3 illustratrates the graphical description of a Weibull plot with varying values of $\eta$ and gammma 
(referred to as the A and $\mathrm{k}$ parameters later in this paper) [9].

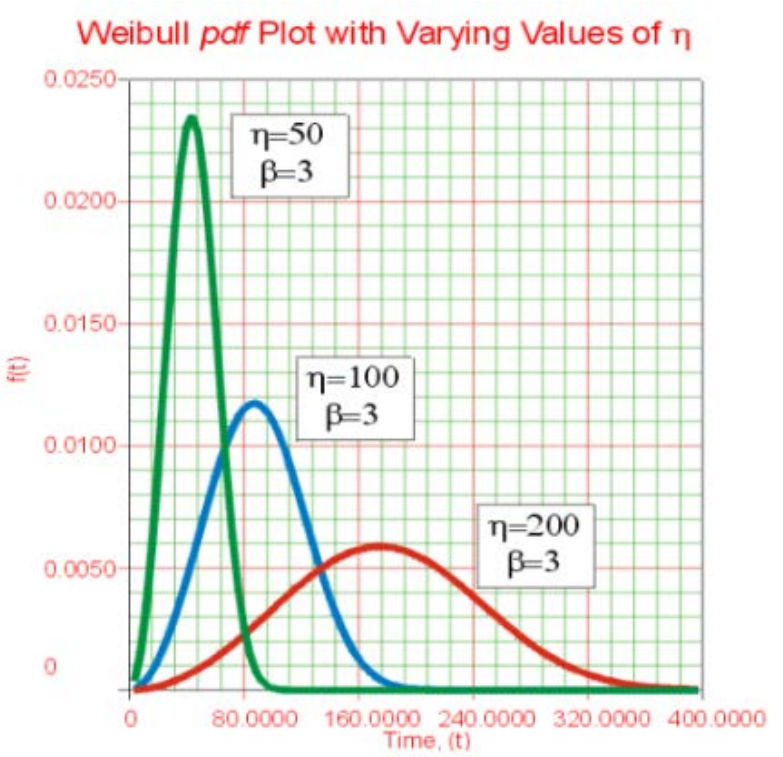

Figure 3: Weibull plot of the probability density function [6].

\subsection{Error metrics}

Error metrics are commonly used to express differences between two time series namely the predicted and measured value as shown in Equation 1.

$$
\varepsilon_{i}=x_{\text {pred }, i}-x_{m e a s, i}
$$

There are a number of common metrics, two of which will be presented in the sub-sections which follow.

\subsubsection{Root mean square error (RMSE)}

RMSE is the most popular evaluation metric used in regression problems. It follows an assumption that error is unbiased and follows a Weibull distribution [9]. Although an initial and rudimentary indicator, RMSE can be used to understand different error sources. It can be described as in Equation 2.

$$
R M S E=\sqrt{\frac{1}{N} \sum_{i=1}^{N} \varepsilon_{i}^{2}}
$$

\subsubsection{Mean absolute error (MAE)}

MAE is the unaltered magnitude i.e. absolute value of each difference in a time series. It is described as shown in Equation 3. MAE can be considered the most natural and unambiguous measure of average error magnitude. For this reason and for the purposes of this study, MAE is considered.

$$
M A E=\frac{1}{N} \sum_{i=1}^{N}\left|\varepsilon_{i}\right|
$$

\subsubsection{Pearson correlation coefficient}

The Pearson correlation coefficient is often described as the best measurement of the association between variables of interest and is shown in Equation 4 [7].

$$
r=\frac{N \sum x y-\left(\sum x\right)\left(\sum y\right)}{\sqrt{\left[N \sum x^{2}-\left(\sum x\right)^{2}\right]\left[N \sum y^{2}-\left(\sum y\right)^{2}\right]}}
$$

Where:

$N=$ number of pairs of data points;

$\sum x y=$ sum of products of paired points;

$\sum x=$ sum of $\mathrm{x}$ points;

$\sum y=$ sum of $y$ points;

$\sum x^{2}=$ sum of squared $\mathrm{x}$ points;

$\sum y^{2}=$ sum of squared y points.

\subsection{Power conversion}

The power conversion method used is simply a power curve applied to a particular location's Weibull distribution. Generally, wind turbines begin operating at wind speeds between 4 and $6 \mathrm{~m} / \mathrm{s}$ and can reach a maximum power output at around 15 $\mathrm{m} / \mathrm{s}$. with safety cut-off speeds at approximately 25 $\mathrm{m} / \mathrm{s}$. The average electrical production from a wind turbine occurs 70-85\% of the time but does not necessarily generate the maximum electrical power all the time, due to varying wind speeds [8]. This means that the capacity factor calculations only demonstrate the theoretical maximum which can be generated.

The WCFC determines the Weibull distribution from $\mathrm{A}$ and $\mathrm{k}$ parameters derived from a reduced dataset. A Weibull distribution can be expressed in terms of the wind speed, as shown in Equations 5 and 6.

$$
\begin{aligned}
& f\left(V_{\text {wind }}\right)=\left(\frac{k}{A}\right)\left(\frac{V_{\text {wind }}}{c}\right)^{k-1} \exp \left(-\left(\frac{V_{\text {wind }}}{A}\right)^{k}\right) \\
& f(x, \lambda, k)=\frac{k}{\lambda}\left(\frac{x}{\lambda}\right)^{k-1} e^{-\left(\frac{x}{\lambda}\right)^{k}},\{x \geq 0, k>0, \lambda>0\}
\end{aligned}
$$

Where:

$f\left(V_{\text {wind }}\right)=$ probability of observing wind speed;

$k=$ dimensionless Weibull shape parameter;

$A=$ Weibull scale parameter;

$V_{\text {wind }}=$ wind velocity $(\mathrm{m} / \mathrm{s})$.

\subsection{Types of wind turbines}

Table 1 displays the different types of turbines considered use within the WCFC. The turbine technical specifications are outlined

\subsection{Description of tool}

The WCFC is modelled through the programming language called Python [13]. Python version 3.7 
Table 1: Types of turbines considered for WCFC [9] [10] [11] [12].

\begin{tabular}{|c|c|}
\hline Types of turbines & Properties \\
\hline Alstom ECO & $\begin{array}{l}\text { Rated Power }=3.0 \mathrm{MW} \\
\text { Cut-in wind speed }=3.0 \mathrm{~m} / \mathrm{s} \\
\text { Rated } \text { wind speed }=12 \mathrm{~m} / \mathrm{s} \\
\text { Cut-off } \text { wind speed }=25 \mathrm{~m} / \mathrm{s} \\
\text { Rotor Diameter }=100 \mathrm{~m} \\
\text { Rotor blades }=3 \\
\text { Swept Area }=7980 \mathrm{~m}^{2} \\
\text { Tip speed }=74 \mathrm{~m} / \mathrm{s} \\
\text { Gear box }=\text { Spur } / \text { planetary } \\
\text { Generator type }=\text { Asynchronous } \\
\text { Grid frequency }=50 \mathrm{~Hz} \\
\text { Tower height }=75 / 90 / 100 \mathrm{~m}\end{array}$ \\
\hline GE Wind Ener & $\begin{array}{l}\text { Rated Power }=2,75 \mathrm{MW} \\
\text { Cut-in wind speed }=3.0 \mathrm{~m} / \mathrm{s} \\
\text { Rated wind speed }=13 \mathrm{~m} / \mathrm{s} \\
\text { Cut-off wind speed }=25 \mathrm{~m} / \mathrm{s} \\
\text { Rotor Diameter }=103 \mathrm{~m} \\
\text { Rotor blades }=3 \\
\text { Swept Area }=8332 \mathrm{~m}^{2} \\
\text { Gear box }=\text { Spur } / \text { planetary } \\
\text { Generator type }=\text { Double fed Async } \\
\text { Grid frequency }=50 / 60 \mathrm{~Hz} \\
\text { Tower height= } 75 / 85 / 98.3 / 123.5 \mathrm{~m}\end{array}$ \\
\hline Nordex N131 & $\begin{array}{l}\text { Rated Power }=3.0 \mathrm{MW} \\
\text { Cut-in wind speed }=3.0 \mathrm{~m} / \mathrm{s} \\
\text { Cut-off wind speed }=20 \mathrm{~m} / \mathrm{s} \\
\text { Rotor Diameter }=131 \mathrm{~m} \\
\text { Rotor blades }=3 \\
\text { Swept Area }=13478 \mathrm{~m}^{2} \\
\text { Tip speed }=80 \mathrm{~m} / \mathrm{s} \\
\text { Gear box }=\text { Spur } / \text { planetary } \\
\text { Generator type }=\text { Double fed Async } \\
\text { Grid frequency }=50 / 60 \mathrm{~Hz} \\
\text { Tower height }=99 / 114 / 134 \mathrm{~m}\end{array}$ \\
\hline Vestas_V90 & $\begin{array}{l}\text { Rated Power }=3.0 \mathrm{MW} \\
\text { Cut-in wind speed }=4.0 \mathrm{~m} / \mathrm{s} \\
\text { Rated wind speed }=15 \mathrm{~m} / \mathrm{s} \\
\text { Cut-off wind speed }=25 \mathrm{~m} / \mathrm{s} \\
\text { Rotor Diameter }=90 \mathrm{~m} \\
\text { Rotor blades }=3 \\
\text { Swept Area }=6362 \mathrm{~m}^{2} \\
\text { Tip speed }=87 \mathrm{~m} / \mathrm{s} \\
\text { Gear box }=\text { Spur } / \text { planetary } \\
\text { Generator type }=\text { Asynchronous } \\
\text { Grid frequency }=50 \mathrm{~Hz} \\
\text { Tower height }=80 / 105 \mathrm{~m}\end{array}$ \\
\hline
\end{tabular}

was used, which suited the requirements for general purpose programming. The coding language was used for various reasons: It is open source, and accessible to anyone online; It is user-friendly with widely published explanatory documentation available; and it contains useful libraries for everything required in the WCFC development. The raw data being used from dataset 1 was analysed using the NetCDF Python libraries (network common data format).

\section{Methodology}

\subsection{App development methodology}

The WCFC development methodology is outlined in the flow-diagram in Figure 4, which demonstrates the following critical steps:

\section{Raw data:}

CSIR PV/wind aggregation study wind timeseries data (dataset 1) in NetCDF format.
2. Data reduction:

a) Reduce the 15-minute time series data to yearly averages.

b) Reduce the $15 \mathrm{MB}$ NetCDF format to $1 \mathrm{~KB}$ txt files per GPS location, having parameters given in Table 2.

\section{Data analysis:}

a) 'On the fly' generation of the AEP and capacity factor results for the requested GPS location.

b) Verification of the results attained, through the Pearson correlation coefficient and the RMSE.

c) Dataset comparison between original and reduced dataset outputs.

4. Build graphical user interface (GUI) and results: Build GUI for the tool to allow the user to log in GPS coordinates and select the turbine. This then outputs the AEP and frequency profile over the wind speed at all four heights.

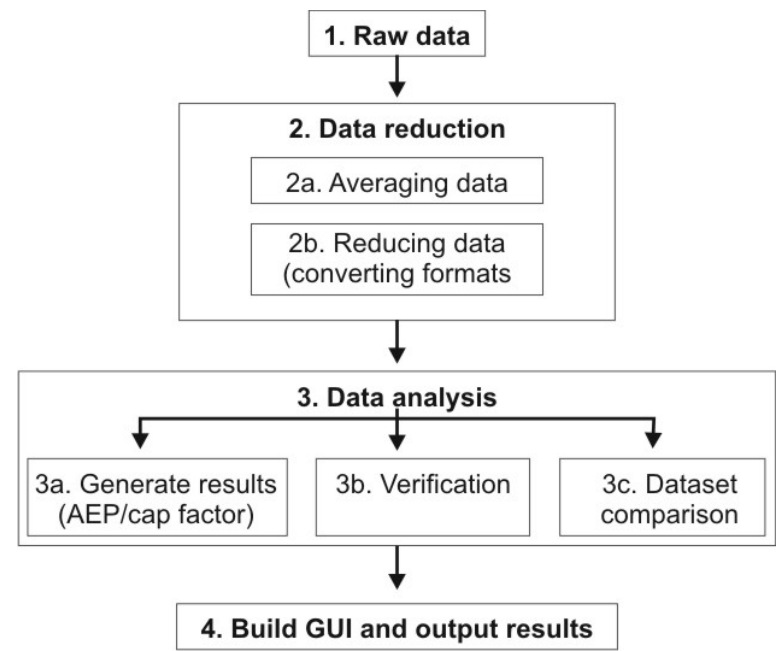

\section{Figure 4: App development methodology flow} diagram.

\subsection{Data reduction process}

The main reason for reducing the large datasets was to develop a tool which is capable of easy download and operates faster. In order to reduce the data, the WCFC allows users to convert different data file formats to the desired data file format, in this case from a $15 \mathrm{MB}$ or raw data per file to a $1 \mathrm{~KB}$ file that carries all the critical information needed, i.e. the Weibull A and $\mathrm{k}$ parameters. Reduced data in this form allows future opportunity to convert the WCFC into an app which operates on both Android and Apple's IOS.

Table 2 shows the parameters by which the Weibull curve will be plotted. In turn, the AEP and the capacity factor over the four different heights will be determined as the desired outcome. As part of the reduction process error metrics, the Pearson correlation coefficient and RMSE are generated. 
Table 2: Reduced data format

50m k A Ave. Ave. Pearson RMSE speed density

$80 \mathrm{~m}$ k A Ave. Ave. Pearson RMSE speed density

$100 \mathrm{~m} \mathrm{k} \mathrm{A}$ Ave. Ave. Pearson RMSE speed density

$150 \mathrm{~m} \mathrm{k} \mathrm{A} \mathrm{Ave.} \mathrm{Ave.} \mathrm{Pearson} \mathrm{RMSE}$ speed density

The flow diagram in Figure 5 demonstrates the process to operate the resultant WCFC.

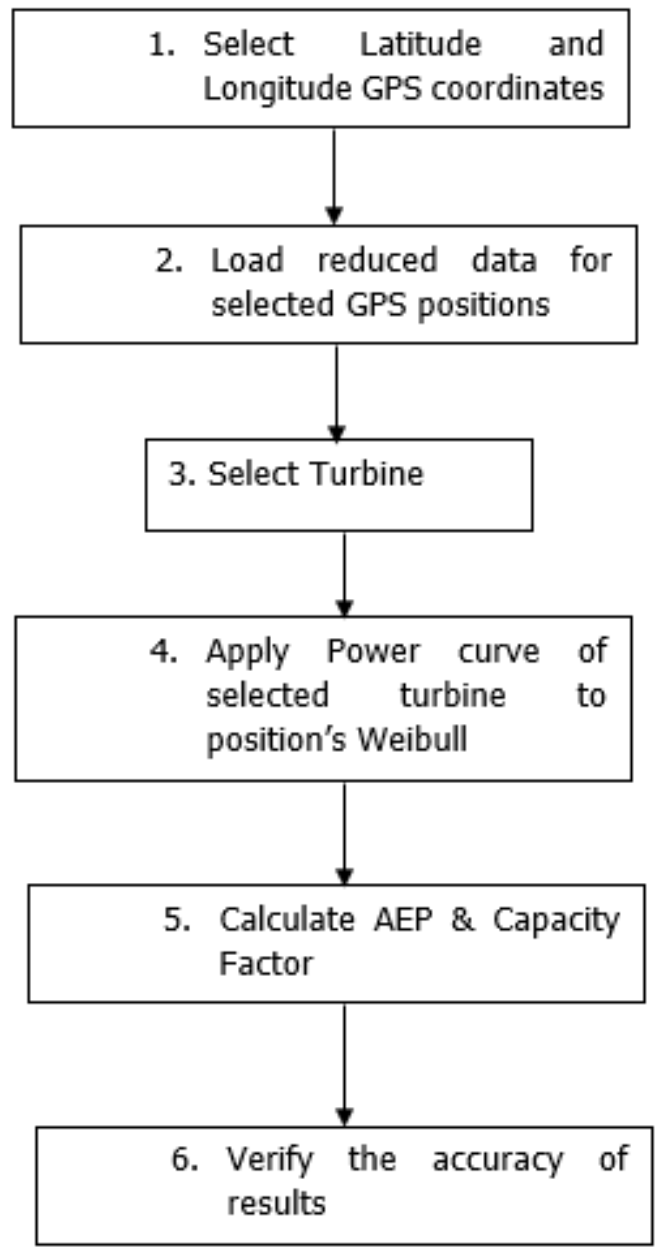

Figure 5: Operation of the app's flow-diagram.

\subsection{Methodology of error analysis}

The error analysis was conducted by selecting 15 random points to form part of a comparative study. The comparative study will analyse the difference in AEP and capacity factory output per location. The latest WASA is considered the more up to date dataset because, firstly, better verification was carried out during the data capturing process; and, secondly, Advanced research led to greater understanding on the effective methods of data capturing which aided the WASA data accuracy

\section{Results}

The figures below show the outputs given by the GUI and comparisons between dataset 1 and dataset 2 in terms of AEP and capacity factor for given turbines.

\subsection{Graphical user interface outputs}

The GUI and resulting power curve vs. Weibull distribution outputs are shown in Figures 6 and 7.

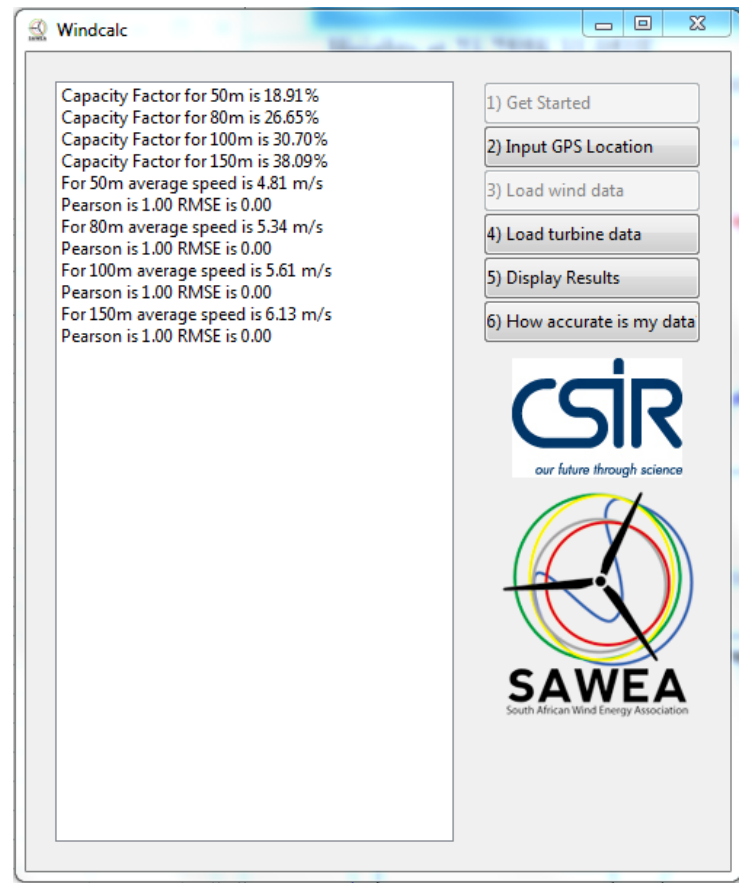

Figure 6: Graphical user interface for generating results from the WCFC.

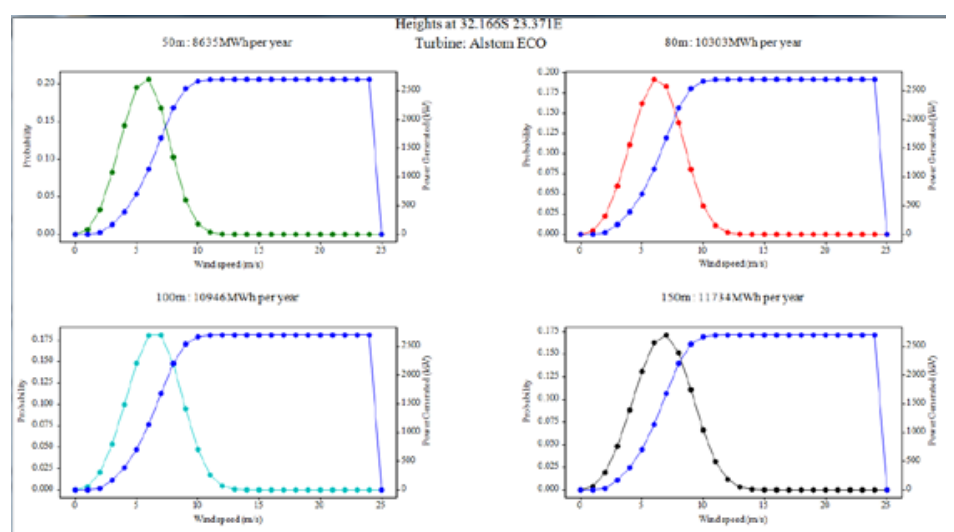

Figure 7: WCFC displaying the AEP graph over four heights.

\subsection{Dataset comparisons}

5.2.1 Annual energy production

Figures 8 to 11 display the AEP for each dataset over 15 points at the preferred turbine height. 


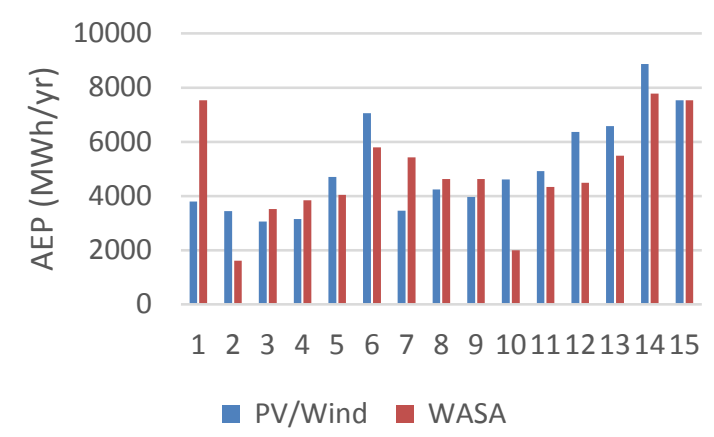

Figure 8: Vestas_V90 AEP at $100 \mathrm{~m}$.

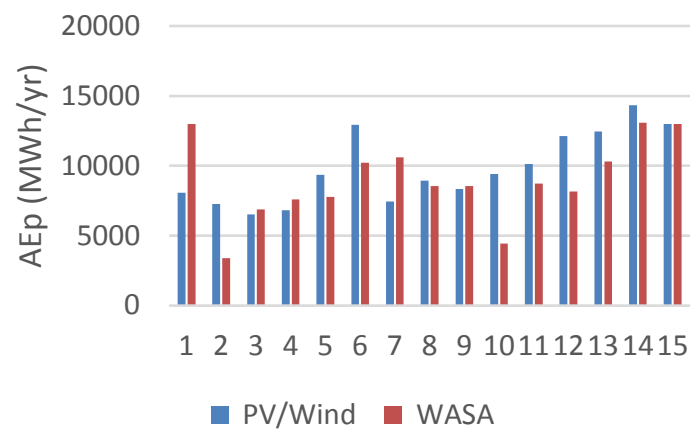

Figure 9: Nordex N131 AEP at $100 \mathrm{~m}$.

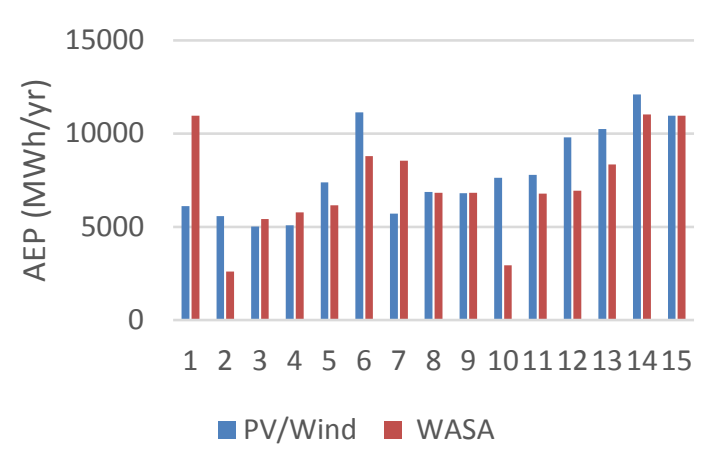

Figure 10: GE Wind Energy 2.75 AEP at $80 \mathrm{~m}$.

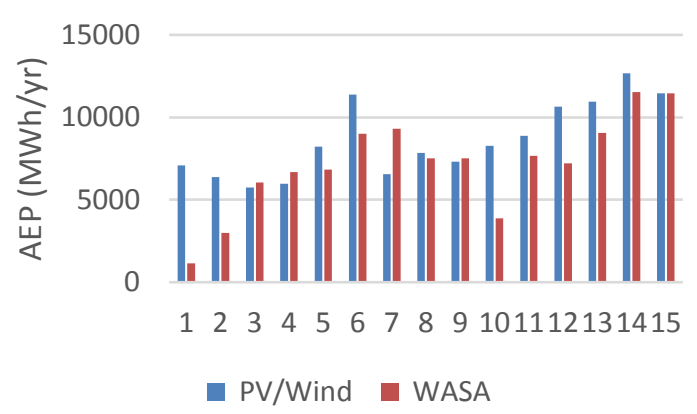

Figure 11: Alstom ECO AEP at $100 \mathrm{~m}$.

5.2.2 Capacity factor

Figures 12-15 display the capacity factor (\%) for each dataset over 15 points at the preferred turbine height.

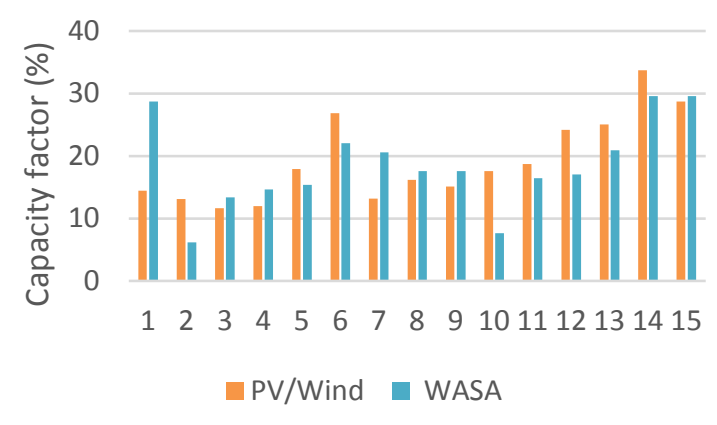

Figure 12: Vestas_V90 capacity factor at $100 \mathrm{~m}$.

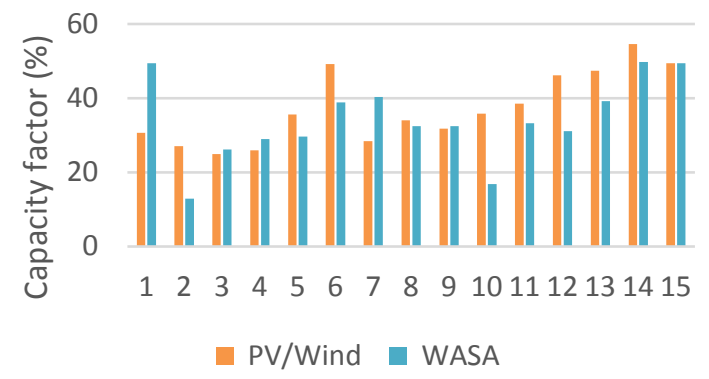

Figure 13: Nordex N131 capacity factor at $100 \mathrm{~m}$.

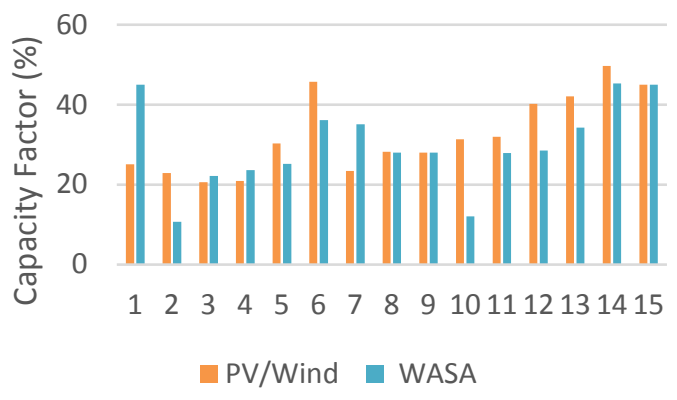

Figure 14: GE wind energy 2.75 capacity factor at $80 \mathrm{~m}$.

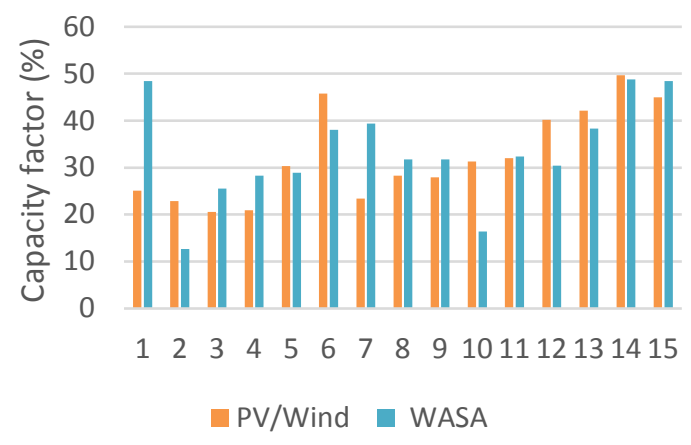

Figure 15: Alstom ECO capacity factor at $100 \mathrm{~m}$.

5.3 Wind capacity factor calculator results discussion

5.3.1 Reduced data

When comparing dataset 1 to its reduced equivalent, the major difference is that the original NetCDF 
files were replaced with text files containing Weibull parameters to approximate the same data. What this means is that the data could be used with between 90\% and $99 \%$ confidence when using the Pearson correlation coefficient and RMSE generally close to zero.

\subsubsection{WCFC output verification}

To verify the outputs of the WCFC, the capacity factors provided were compared to already-calculated capacity factors for the CSIR pre-feasibility study conducted to determine whether a wind turbine installation for research purposes was possible at four possible locations across South Africa (see Table 3). Bar one instance, the WCFC has produced results within $\sim 15 \%$ of those already verified in the CSIR study, thus indicating acceptable operation. It is, however, suggested that further verification be conducted.

Table 3 PV/wind vs CSIR pre-feasibility

\begin{tabular}{ccc}
\hline $\begin{array}{c}\text { WCFR capacity } \\
\text { factor (\%) }\end{array}$ & $\begin{array}{c}\text { CSIR pre-feasibility } \\
\text { capacity factor (\%) }\end{array}$ \\
\hline 1 & 18 & 17 \\
2 & 10 & 26 \\
3 & 23 & 28 \\
4 & 35 & 33 \\
\hline
\end{tabular}

\subsubsection{Comparison of datasets 1 and 2}

The results given in table 3indicate that in locations like point 1,2, 7 and 10, difference between the two datasets is noticeable. It is suggested that this difference results from possible inaccurate pixel overlap of the two datasets. The difference in (XY) coordinates centre points is impactful to the AEP and capacity factor values. Therefore, when interpreting the obtained results, one must consider the measure of overlap.

\section{Conclusion}

Since the report aimed to demonstrate whether both datasets are suitable for use, it can be deduced that when the coordinates from the latest WASA data (dataset 2) and the CSIR PV/wind aggregation study (dataset 1) data are same without overlap, the difference between the two datasets is within $5 \%$. Some work still needs to be done at positions where this overlap is not exact however for high level use, it can be concluded that either dataset can be used to obtain reasonable high level results. Overall, WCFC operation has been verified at a high level against CSIR conducted studies, providing acceptable results at this stage of its development.

\section{Author roles}

Hlologelo Kekana: Modelled the WCFC, cleaned and analysed the data for modelling, report write-up

Greg Landwehr: Data collection, supervising and editing final drafts.

\section{References}

[1] C. Ajaokorie, An Overview of Wind Power in Africa, Novia: University of Applied Acience, Vaasa, 2016.

[2] H. J. Carsten, Wind Atlas for South Africa (WASA) Best practice guide for application of WASA, Technical University of Denmark: department of Wind Energy, Roskilde, Denmark, 2014.

[3] New energy update.com, Wind energy update, New energy update.com, 15 July 2010. [Online]. Available: http://newenergyupdate.com/wind-energy-update/wind-energy-output-modelling-weibull-correlation. [Accessed 15 October 2018].

[4] WindPower Program, Wind turbine power ouput variation with steady wind speed., WindPower Program, [Online]. Available: http://www.wind-power-program.com/turbine_characteristics.htm. [Accessed 08 October 2018].

[5] www.windpower.org, Dansih Wind Industry Association, www.windpower.org, 13 Septemeber 2003. [Online]. Available: http://xn--drmstrre-64ad.dk/wp-content/wind/miller/windpower\%20web/en/tour/wres/annu.htm. [Accessed 16 October 2018].

[6] HBM Prenscia Inc., www.weibull.com, Reliability Hot Wire, 2018. [Online]. Available: https://www.weibull.com/hotwire/issue14/relbasics14.htm. [Accessed 23 September 2018].

[7] Statistic Solutions, Pearson's Correlation Coefficient, Complete Dissertation, 2018. [Online]. Available: http://www.statisticssolutions.com/pearsons-correlation-coefficient/. [Accessed 09 October 2018].

[8] EWEA, Wind energy basics, EWEA, 2018. [Online]. Available: http://www.ewea.org/wind-energy-basics/faq/. [Accessed 23 September 2018].

[9] Nordex Online, Nordex N131/3000, Nordex, 2018. [Online]. Available: http://www.nordexonline.com/en/produkte-service/wind-turbines/n131-30-mw.html. [Accessed 08 October 2018].

[10] S. Matysik, wind-turbine.com, General Electric, 12 October 2016. [Online]. Available: http://www.windturbine.com/general-electric-2.75MW. [Accessed 10 October 2018].

[11] A. Tobias, Vestas V90-3.0, wind-turbine.com, 09 February 2015. [Online]. Available: https://en.wind-turbinemodels.com/turbines/16-vestas-v90. [Accessed 12 October 2018]. 
[12] C. English, Alstom ECO 100-3MW, wind-turbine.com, 2011. [Online]. Available: https://en.wind-turbinemodels.com/turbines/793-alstom-eco-100. [Accessed 08 October 2018].

[13] Python, Python, Python Software foundation, 2018. [Online]. Available: https://www.python.org/. [Accessed 12 October 2018].

[14] N. G. M. e. a. Jens Carsten Hansen, Wind atlas for South Africa (WASA), Western Cape and parts of Northern and Eastern Cape, Department of Energy, SANEDI, CSIR, SAWS, UCT, DTU, Cape Town, 2014.

[15] windhunter.com, Windhunter_africa, Windhunter_serwis, 2018. [Online]. Available: http://windhunter.co.za/en/products-services/met-masts/. [Accessed 08 October 2018].

[16] T. Bischof-Niemz, Energy Mix 2.0: The Potential for a New Paradigm, Counsel for Scientific and Industrial Reseach (CSIR), Johannesburg, 2017.

[17] S. A. Prem Kumar Chaurasiya, Study of different parameters estimation methods of Weibull distrubtion to determine Wind power density using ground based Doppler SODAR instrument, Alexandra Engineering Journal, vol. 1, no. 1, pp. 1-13, 2017.

[18] D. Milborrow, Gaining a better understand of capacity factor, productivity and efficiency, www.windpowermonthly.com, 7 December 2012. [Online]. Available: https:/www.windpowermonthly.com/article/1163492/gaining-better-understanding-capacity-factor-productivityefficiency. [Accessed 09 October 2018].

[19] N. Sematech, Exploring Data Analysis, www.itl.nist.gov, 2018. [Online]. Available: https://www.itl.nist.gov/div898/handbook/eda/section3/eda3668.htm. [Accessed 12 October 2018].

[20] R. Gaughan, Wind Turbine size vs Power, Sciencing.come, 25 April 2017. [Online]. Available: https://sciencing.com/wind-turbine-size-vs-power-23676.html. [Accessed 10 October 2018].

[21] D. E. Watson, Wind Turbine Power Coefficienct, FT Exploring Science \& Technology, 2015. [Online]. Available: http://www.ftexploring.com/wind-energy/wind-power-coefficient.htm. [Accessed 16 October 2018].

[22] L. Caretto, Use of Probability Distribution Functions for Wind, California State University: Northridge , Los Angeles, 2010. 